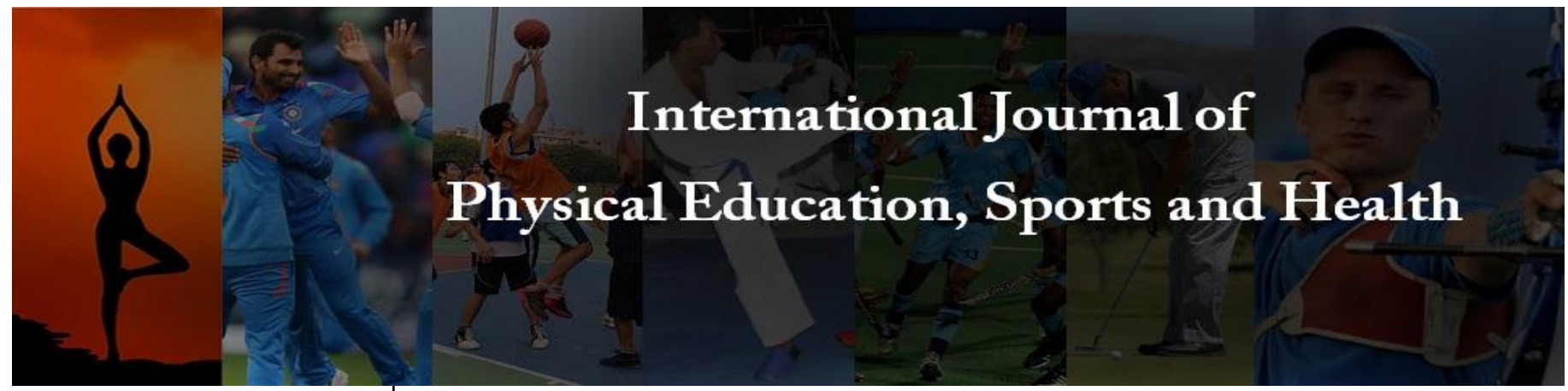

P-ISSN: 2394-1685

E-ISSN: 2394-1693

Impact Factor (ISRA): 5.38

IJPESH 2022; 9(1): 425-427

(C) 2022 IJPESH

www.kheljournal.com

Received: 23-11-2021

Accepted: 29-12-2021

\section{Debabrata Sarkar}

Research Scholar, Department of

Physical Education, Guru

Ghasidas Vishwavidyalaya,

Bilaspur, Chhattisgarh, India
Corresponding Author:

Debabrata Sarkar

Research Scholar, Department of

Physical Education, Guru

Ghasidas Vishwavidyalaya,

Bilaspur, Chhattisgarh, India

\section{Effect of Surya namaskar on selected physical fitness variables of physical education students}

\section{Debabrata Sarkar}

DOI: https://doi.org/10.22271/kheljournal.2022.v9.i1g.2412

\section{Abstract}

The purpose of the study was to find out the effect of Surya namaskar on selected physical fitness variables of Bachelor of physical education Students. For this study 40 Bachelor of physical education Students were selected from Bilaspur using purposive sampling technique. The pre-test was conducted on flexibility and cardiovascular endurance using sit and reach test and 12 min Cooper test. The age of the subjects ranged from 21 to 26 years. Six weeks training of Surya namaskar practise was performed. Completion of 6 weeks training post test was conducted. Find out the significant difference between pre and post training, paired sample t-test was applied. Result shows that there was a significant difference $(P<0.05)$ due to the Surya namaskar practise on selected physical fitness variables among Bachelor of physical education Students. On the basis of the t-value for flexibility 6.09 and Cardiovascular Endurance 5.98 it was concluded that implication of Surya namaskar practise improves selected physical fitness variables of Bachelor of physical education Students.

Keywords: Surya namaskar, bachelor of physical education, flexibility, cardio vascular endurance etc.

\section{Introduction}

Today, the world is changing very rapidly thanks to science and technology in every field. It brings more benefits and leads to a sedentary lifestyle that makes people become sedentary, thereby increasing the number of harmful diseases in the younger generation.

India is a core place of Yogic practices. Currently Adays yoga the old habit respiratory and contemplation will continue many social insurance experts. With the expansion of a logic exam in yoga its recovery prospects are also studied rescue. Surya namaskar - Welcome to the Sun, and God is also part of India's usual yogic practices. Suryananaskar is best practices in Yogic practice. It's basically 12 exercises each with separate positions and they are worked on the human body. It is to make human life socially satisfying rationally comfortable physically comfortable frankly adaptable and deeply enjoyable.

The word Surya namaskar is related to two words one is Surya and the other is Namaskar it implies that Surya is a kind of fire and Namaskar is a kind of appreciation. Surya namaskar is an evolution of twelve physical positions. These forward and backward bends flex and lengthen the spine to its fullest extent, greatly stretching the entire body. SN improves rest and quiet, improves muscle adaptability, strengthens stomach muscles, and improves human visceral limit and so on. Many such specialists can be found in this area.

Surya namaskar is an old Indian technique for offering requests to God to the rising sun in the morning alongside a progression of physical stances with controlled breathing going for scope of physical, mental and otherworldly advantages (Parag and Manjunath, 2012)

Surya namaskar balances body, mind, consciousness and soul. In this way, Surya namaskar helps us to deal with a holistic effect and daily needs, problems and worries. Surya namaskar helps to better understand self, purpose of life.

Flexibility and cardiovascular endurance are most important factor that can affect the performance of each and every individual. Physical Education students perform various games and sports and they require various physical fitness parameters. Surya namaskar is the combination of twelve stretching, holding and relaxation exercises that is the main factors that increases the flexibility of various muscles as well as Cardiovascular endurance. 


\section{Objectives of the study}

To find out the significant difference between pre and posttest of flexibility and cardiovascular endurance on Bachelor of physical education students.

\section{Hypotheses}

H1 - It was hypothesized there may be a significant difference on Flexibility due to Surya namaskar practice among Bachelor of physical education students.

H2 - It was hypothesized there may be a significant difference on Cardio Vascular Endurance due to surya namaskar practice among Bachelor of physical education students.

\section{Methodology \\ Selection of subjects}

To achieve the purpose of the present study total 40 Bachelor of physical education students were randomly selected using purposive random sampling from Guru Ghasidas Vishwavidyalaya, aged ranged between 21 to 26 years.

\section{Selection of variables}

\section{- Independent variables}

Surya namaskar

\section{- Dependent variables}

Flexibility and Cardio Vascular Endurance

\section{Criterion Measures}

Flexibility was measured by sit and reach test and recorded in centimetre and cardio vascular endurance measured by Cooper 12-minute walk or run test and it's measured by meter. After each set 10 seconds rest was adopted.

\section{Experimental Design}

The study was to find out the effect of surya namaskar practices on selected physical fitness variables among Bachelor of physical education students single group design was used. The total subjects were 40 aged between 21 to 26 years. Data were collected from each subject pre-test and post-test of the 6 weeks of training session, where five days a week and each day 30 minutes of Surya namaskar practiced by the subject. The test items were designed according to purpose of the study and with the use of literature reviews.

\section{Statistical Procedure}

The data were analysed by applying descriptive statistical and paired t-test by the use of SPSS V 26.0. The level of significance was set for the study at 0.05 .

\section{Result and Findings of the Study}

Table 1: Descriptive and comparative statistics of pre and post-test of flexibility

\begin{tabular}{|c|c|c|c|c|c|c|c|}
\hline Variables & Test & N & Mean & Std. Deviation & Std. Error of Mean & t- value & Sig. \\
\hline \multirow{2}{*}{ Flexibility } & Pre & 40 & 32.57 & 1.43 & 0.23 & \multirow{2}{*}{6.09} & \multirow{2}{*}{.000} \\
\cline { 2 - 8 } & Post & 40 & 33.76 & 1.64 & 0.26 & & \\
\hline
\end{tabular}

Table 1 revels that the mean of the pre-test \& post-test of flexibility are $32.57 \& 33.76$ and S.D. $1.43 \& 1.64$ respectively. The obtained t-value for flexibility 6.09 is significant at 0.05 level of significance. The result of the study confirms that significant difference found between the means of pre and post-test in relation to flexibility.

Table 2: Descriptive and comparative statistics of pre and post-test of Cardiovascular Endurance

\begin{tabular}{|c|c|c|c|c|c|c|c|}
\hline Variables & Test & $\mathbf{N}$ & Mean & Std. Deviation & Std. Error of Mean & t- value & Sig. \\
\hline \multirow{2}{*}{ Cardiovascular Endurance } & Pre & 40 & 2561.25 & 124.94 & 19.76 & \multirow{2}{*}{5.98} & \multirow{2}{*}{.000} \\
\cline { 2 - 7 } & Post & 40 & 2617.50 & 112.88 & 17.85 & & \\
\hline
\end{tabular}

Table 2 revels that the mean of the pre-test \& post-test of Cardiovascular Endurance are $2561.25 \& 2617.50$ and S.D. $124.94 \& 112.88$ respectively. The obtained t-value for Cardiovascular Endurance 5.98 is significant at 0.05 level of significance. The result of the study confirms that significant difference found between the means of pre-test and post-test in relation to Cardiovascular Endurance.

\begin{tabular}{|c|c|c|c|c|c|c|}
\hline \multicolumn{7}{|c|}{ Paired Samples Test } \\
\hline & & \multicolumn{3}{|c|}{ Paired Differences } & \multirow{2}{*}{$\mathbf{t}$} & \multirow{2}{*}{ Sig. (2-tailed) } \\
\hline & & Mean & Std. Deviation & Std. Error Mean & & \\
\hline Pair of Flexibility & pre-test post test & 1.18750 & 1.23271 & .19491 & 6.093 & .000 \\
\hline Pair of Cardio Vascular Endurance & Pre-test Post-test & 56.25000 & 59.51460 & 9.41008 & 5.978 & .000 \\
\hline
\end{tabular}

\section{Discussion on Hypotheses}

As per the result of used test and data interpretation the Hypotheses H1 \& H2 was accepted.

\section{Conclusion}

On the basis of the results of the study indicates that: -

Through this study we find out that the Surya namaskar practices improves the physical fitness variables.

Through this study we can suggests that surya namaskar practices to all the Bachelor of physical education students for improving their selected physical fitness variables.

\section{References}

1. Dr. Ratnesh Singh, Kunvar Singh. Effect of eight weeks training of Surya namaskar on flexibility of cricket players. IJAR 2016;2(4):665-667.

2. Choudhary R, Krzytof Stec. The effect of dynamic Surya Namaskar on flexibility of university students. J.A.D. Research. 2010;1(1):45-48.

3. Sinha Biswajit et al. "Comparison of Cardiorespiratory Responses between Surya- namaskar and Bicycle Exercise at Similar Energy Expenditure Level", Indian Journal of Physiology and Pharmacology. 2013;57(2):169-176.

4. Tamal Chakraborty et al. "Effect of Yogic Exercise on Selected Pulmonary Function Tests in Apparently Healthy Elderly Subjects", IOSR Journal of Dental and Medical Sciences (IOSRJDMS). 2013;9(1):01-05. 
Vinayak.

5. Mishra MK, Pandey AK, Dubey S. Effect of eight weeks yogic training on selected physiological variables. IJPESH 2015;1(3):16-18.

6. Singh Amandeep, Singh Sukhdev, Gaurav Vishaw. Effects of 6-Weeks Yogasanas Training on Agility and Muscular Strength in Sportsmen. International Journal of Educational Research \& Technology. 2011;2(2):72.

7. Doijad P, Anil Surdi D. "Effect of Short Term Yoga Practice on Pulmonary Function Tests", IJBAMR, 2012;3(1):226-230. 